Espacio, Tiempo y Forma, Serie III, H. Medieval, t. 17, 2004, págs. 571-587

\title{
Aproximación al estudio de los judíos de Alcalá de Henares en la Edad Media
}

\author{
Gonzalo Viñuales Ferreiro ${ }^{1}$
}

RESUMEN

La villa de Alcalá de Henares (Madrid) contó con una importante aljama judia durante la Euad Media, por lo menos desde 1118 hasta 1492. Con este artículo pretendemos ofrecer una aproximación a

diversos aspectos que caracterizaron a esta comunidad hebra como la localización de la juderia, funcionamiento de las instituciones comunales, actividades económicas desempeñadas por los judios, relación con los poderes de la villa, su expulsión, etc.

\section{PALABRAS CLAVE}

Alcalá de Henares, Edad Media, Aljama judía, Conversos.

\section{ABSTRACT}

The city of Alcalá de Henares (Madrid) had got an important Jewish quarter during the Middle Age, at least from 1118 to 1492 . With this article we try to inform about some of the characteristics of this community: jewish quarter situation, communal institutions organisation, jew's professions, relations with the christian authorities of the city, the expulsion, etc.

\section{KEY WORDS}

Alcalá de Henares, Middle Age, Jewish quarter, Converted Jews.

A lo largo de la Edad Media un importante número de judíos eligió la villa de Alcalá de Henares para vivir y trabajar. Compraron y alquilaron casas, labraron la tierra, recogieron cosechas, fueron comerciantes y tejieron prendas de vestir, fabricaron objetos de plata, curaron enfermos, y recaudaron impuestos. Habitaron entre cristianos y mudéjares, construyeron sus sinagogas y demás edificios de uso público, fundaron cofradias, guardaron el sábado, y partieron al exilio o se convirtieron cuando se decretó su expulsión en 1492.

1 Instituto de Humanidades. Facultad de Ciencias Juridicas y Sociales. Universidad Rey Juan Carlos. 


\section{EL ESPACIO VITAL}

Aprovechando la estratégica ubicación geográfica de la villa, algunos judíos, principalmente comerciantes, se fueron asentando en el eje principal de la ciudad, la vía que unía Toledo y Madrid con Guadalajara y Zaragoza, para instalar sus tiendas y comercios. Estos hebreos fueron dando cuerpo a su propia comunidad, con sus jueces y rabinos, y con su carnicería, sus baños, sus sinagogas y su cementerio propios.

Así pues, la cal pública de la judería, la calle mayor del barrio judío, se convirtió en el primer y principal asentamiento de los semitas en Alcalá, y en torno a ella se expandió la juderia al ir aumentando el número de judios que llegaban a Alcalá de Henares. La presencia hebrea en esa calle, tanto con casas como con tiendas, debía ser tan significativa que la población cristiana se refería a ella por ese nombre, tal y como se demuestra en un documento de 1401 en el que Alfonso González de León, y su mujer, Mari González, donan al cabildo de los clérigos de la villa una "[...] casa tienda con sus cámaras que avemos en la cal de la Judería desta dicha villa [...] ${ }^{2}$. En las cartas de censo que se han conservado, principalmente aquellos establecidos con la iglesia colegial de San Justo y San Pastor, abundan los judíos que tenían arrendadas casas del cabildo en torno a la calle mayor de la judería.

Paulatinamente, los judíos fueron ampliando el marco de su judería hacia la calle de Santiago, también conocida como calle de la Moreria, y las actuales calles de la Imagen y de Cervantes, formando un cuadrilátero bien unificado ${ }^{3}$. Ahora bien, el espacio físico ocupado por los judíos medievales alcalaínos no se constreñiría solamente a esta delimitación, sino que englobaría un espacio mucho más amplio, como bien han señalado José Luis Lacave y Luis Cervera en sus respectivas obras ${ }^{4}$, pues encontramos judios viviendo en la calle de los Tocinos, que iba de la plaza a los palacios arzobispales; en el Mercado, actual plaza de Cervantes; en la plaza de la Picota, cerca de la iglesia de Santiuste, y en la moreria, lindando sus casas con el muro norte de la villa. Un conjunto de calles que bien podrian ser señaladas como los límites del barrio judio.

Sin embargo, las ya citadas cartas de censo de la iglesia colegial sitúan también a población hebrea viviendo en la calle de la Valdreseria, en la calle Real, en la calle de la Vercería, en la calle de los Escribanos, en la calle de las Esparterías, en la calle de Maestre Pedro, en la calle del Matadero, y en la calle de los Roperos ${ }^{5}$. Aunque no tengamos certeza de ello, es muy probable que estas denominaciones aludan a calles que cabían dentro del perimetro de la judería.

Archivo Histórico Nacional. (en adelante, A.H.N.). Clero. Carp. 1341. N. 7

3 Lacave Riaño, J. L: Juderias y sinagogas españolas. Madrid. 1992. Pág. 277.

4 CERVERA VERA, L: El conjunto medieval de Alcalá de Henares y su calle mayor soportalada. Alcalá de Henares. 1987. LaCAVE Riaño, J. L: Juderias y sinagogas españolas. Madrid. 1992.

5 A.H.N. Clero. Legajos (en adelante, Leg), 3553, 3562, 3611. 
La mayor parte de las casas de los judíos en Alcalá se distribuian en torno a corrales o adarves que tenían una entrada pequeña y segura, y se abrían en forma de patio con pozo. En 1456, don Abrahem Burgalés, y Paloma, su mujer, vendian el tributo de censo que tenian sobre unas casas a Lope Ferrández de Alcalá "[...] en las cuales dichas casas hay [...], e más adentro, un patín con su pozo e pala, y junto a él, un vergel cercado [... ") ${ }^{6}$. Lo normal era que el pozo perteneciera a alguna casa específica pero su aprovechamiento fuese de uso comunitario, como demuestra una carta de censo de 1474, en la cual Pero Ruiz de Riaza, en nombre del cabildo de los clérigos de la villa de Alcalá da en censo a Jaco Açaban, "[...] unas casas con su tienda y cámaras, y el pertenescio que tiene de entrar y salir por un postigo a las casas que son de herederos de don Mosé Açaban, platero, que pasan a las dichas casas para sacar agua del pozo de las dichas casas, que son en la calle mayor de la judería [...]"?

Asi, se documentan judios viviendo en el corral de Orvaneja, en el de los Açabanes o del Carrillo, en el corral de la compaña de los judios, en el corral mayor, en los corrales de Elvira García, en el corral y adarves de la sinoga, en el corral de Alonso Ximénez, en el corral de Francisco García Dorado, y en el corral de Justo de Bonilla, que se ubicarían, en su mayor parte, en la judería o en sus proximidades.

Las casas solían tener dos alturas, y muchas presentaban salientes en forma de voladizos lo que les permitía ganar espacio. La distribución interior de las viviendas judías no difiere de las cristianas, salvo por procurar un mayor aislamiento hacia el exterior. El 19 de junio de 1492, siendo inminente la partida de la minoría judía de Alcalá, don Ysaque Açaban, judío, platero, vendía a Francisco López de Piasencia, tesorero de la iglesia colegial de Santiuste, "[...] unas casas en el corral de los Açabanes, que se dice el corral del Carrillo, en que hay una escalera, e a la subida de ellas, un entresuelo, e arriba a la mano izquierda, una cámara grande de una ventana que da en el corral; a la mano derecha, un corredor pequeño, e más adentro, una cocina con su chimenea $[\ldots]{ }^{8}$.

Además de las viviendas particulares, la comunidad judia contaba con edificios públicos, muy relacionados con su carácter de grupo religioso. Necesitaban un lugar donde reunirse a orar, la sinagoga; un lugar donde comprar carne kasher, la carnicería de los judíos; otro donde realizar sus abluciones rituales, el mikwé; y otro, donde dar sepultura a sus difuntos, el cementerio.

Lamentablemente, no se ha conservado ningún resto arqueológico de estos edificios, de tal manera que hemos de guiarnos para su conocimiento exclusivamente por la documentación. En Alcalá de Henares se ha confirmado la

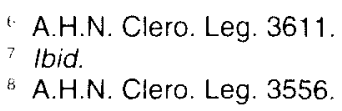


existencia de dos sinagogas ${ }^{9}$. A la Sinagoga Mayor, situada en el número 10 de la calle Carmen Calzado, se accedía por el corral que se llama de la Sinoga, pues aparece mencionada en algunos censos de casas como "[...] casas que solian ser Sinoga Mayor de los judios, en el corral de la sinoga [...]" ${ }^{10}$. Fue en esta sinagoga donde en 1395 el arzobispo de Toledo, Pedro Tenorio, nombró a maestre Pedro, alcalde y juez mayor de todas las aljamas de su arzobispado. La otra sinagoga la ubica E. Azaña, y J. L. Lacave con él, en la esquina entre la calle de Santiago y la calle de Diego de Torres ${ }^{11}$.

La carnicería de los judíos la situaba Ramón Santa María entre la calle Mayor y la calle de Santiago, a partir de una escritura de censo impuesto en 1501 sobre "[...] unas casas y horno entre la calle mayor, y la de Santiago, las que fueron carnicería de los judios [...]" ${ }^{12}$. Sin embargo, el 19 de octubre de 1547, en un pleito sobre el cobro del juro de las carnicerías de los judios, varios testigos, entre ellos, Hernando de Santorcaz, de más de 80 años, declara que «[...] los judios tenian una casa donde ellos mataban la carne y la pesaban, que son y eran en el mismo sitio que agora, en las que dicen las carnicerías del mercado [...]" 13, y otro testigo, Juan Madridano "el viejo", lo corrobora afirmando que "[...] los judios tenían sus carnicerias en las que agora dicen del mercado, y que cierto tiempo después de ser idos los judios, vio esta carnicería hecha horno de pan cocer, y después de cierto tiempo vio a Alonso López de Huerta (converso), tiñiendo el horno y hacerlo bodega [... $]^{14}$. En el proceso inquisitorial contra Gómez de la Torre, comenzado en 1490, se afirma que se asaltó y robó la carnicería. Aunque no se indica el apelativo de los judios, parece muy probable que se tratara de ella ${ }^{15}$.

El cementerio u osario lo ubica Esteban Azaña en el actual parque O’Donnell, y Antonio Castillo cerca de la ermita de San Isidro. La única referencia documental que hemos encontrado sobre el cementerio judio alcalaíno se inserta en el documento inquisitorial que se acaba de mencionar. En esa probanza de los testigos de 1547, dos de ellos, Pedro Manuel y Francisco de Hormero, mayores de 70 años, atestiguan que «[...] los judios tenian un onsario de media legua en largo, donde se enterraban, y era desde la puerta de Santiago, como van camino de Meco $[. . .]^{16}$, lo que modifica las interpretaciones precedentes. También declara Hernando de Santorcaz, quien reitera la opinión anterior, y añade que «[...] alli

9 Ya en la "Respuesta de los rabies a Pedro Ferruz", poeta que compuso a la muerte de Enrique II y que figura entre los más antiguos autores de composiciones líricas incluidas en el "Cancionero de Baena", se hace referencia a las dos Sinagogas de Alcalá de Henares, la denominada "Sinagoga Mayor de los Judíos", y la sinagoga del Adarve de Albornoz.

14. A.H.N. Clero. Leg. 3597.

11 Lacave, J. L: Op. cit., p. 278.

1. Santa Maria, R: "Edificios hebreos en Alcalá de Henares". Boletin de la Real Academia de la Historia. XVII. (1890). pp. 184-189

13 A.H.N. Clero. Leg. 3577.

14 Ibid.

A.H.N. Inquisición (en adelante, INQ.), Leg. 185. Exp. 17.

16 A.H.N. Clero. Leg. 3577. 
[donde estaba el onsario) pacia la hierba la villa de Alcalá [...]" "17, esto es, que aquellos terrenos habian pasado a formar parte de los pastos comunales del concejo de Alcalá, como había sucedido tras la expulsión de los judíos, en otras diversas localidades hispánicas ${ }^{18}$.

Por último, tenemos constancia de la existencia de un mikwé o baño ritual. En el proceso que la Inquisición sigue por judaizante contra Juana Díaz de la Puente, vecina de Alcalá de Henares, declara la acusada en 1490 que «[...] fue con una judía al baño e no se bañó $[. . .]^{19}$. Sin duda, se trata de un baño ritual judío, y Juana Díaz de la Puente quería demostrar que había acudido a él acompañando a una judía, pero que no lo había usado. Pese a que no existe ninguna noticia documental acerca de su posible localización, lo más probable es que ocupara alguna pequeña estancia aneja a la sinagoga mayor, como era habitual en las juderias medievales hispanas.

Estos edificios de carácter público, para toda la población judia, pertenecían a la aljama, pero no eran los únicos. Ésta solía contar con otras propiedades, casas y tierras, de donde obtenia ingresos para atender los gastos de los edificios públicos, para pagar a los rabinos, o ayudar a viudas y huérfanos. En Alcalá de Henares, poseía la aljama casas en la calle Mayor, que daban al corral y adarve que solian ser de la xinoga, que fueron dadas a censo en 1505 por Francisco de Aguayo, contador mayor del arzobispo de Toledo, a Hernando de Talavera, vecino de Alcalá, "[...] las cuales dichas casas primeramente fueron del aljama de los judíos de esta villa [de Alcalá] [...]” ${ }^{20}$.

\section{PRESENCIA HISTÓRICA}

En 1135 el arzobispo de Toledo, don Raimundo, señor de Alcalá de Henares, a quien le habia sido donada la villa en 1129 por el rey Alfonso VII, concedia fuero a sus habitantes; en él establecía los mismos derechos tanto para los judíos como para los cristianos. Aunque podría ser considerada una medida tomada con el objeto de favorecer la repoblación de la villa, sin embargo, esta disposición se mantiene en el Fuero Viejo de 1223 del arzobispo don Rodrigo, al menos en cuanto respecta a la muerte de un judío o un cristiano, y las caloñas consiguientes que debian satisfacerse.

Pero todo parece indicar que durante la undécima centuria ya vivian judios en la Alcalá islámica, favorecidos por el comercio y la aceptación de los musulmanes;

Ibid.

i* Asi, entre otras, en Vitoria (José AMADOR DE LOS RIOS, Historia social, politica y religiosa de los judios de España y Portugal. Madrid, 1875, vol. III, pp. 610-611); en Calahorra, (Enrique CANTERA MONTENEGRO, Las juderias de la diocesis de Calahorra en la Baja Edad Media. Logroño, 1986, pág. 123), y en Toledo (Pilar Leon TEllo, Judios de Toledo. Madrid. 1979. vol. I. pp, 361-362 y 548-549).

19 A.H.N. INQ. Leg. 143. Exp. 8.

20 A.H.N. Clero. Leg. 3566. 
de este modo cuando cae la villa definitivamente del lado de los cristianos, en 1118 , los conquistadores se encuentran con población hebrea ${ }^{21}$.

La bonanza económica de la aljama hebrea de Alcalá de Henares se manifiesta en las elevadas contribuciones que satisface a la hacienda regia, ya desde época temprana. En 1264, Alfonso X establecía la cabeza de pecho de los judíos de Alcalá en 9.627 mrs. Treinta años después Sancho IV, en Huete, recibia de la comunidad hebrea complutense $6.800 \mathrm{mrs}$. por el mismo concepto. $Y$ ya en el siglo XIV, Alfonso $X I$ vuelve a determinar una derrama sobre los judios alcalaínos en concepto de cabeza de pecho, de 9.627 mrs., lo mismo que hará Enrique II en 1366 y en 1373.

Las violentas persecuciones que asolaron las juderías hispanas en 1391 no tuvieron gran repercusión en la villa de Alcalá, de forma que no existe constancia de posibles desmanes o abusos cometidos contra su comunidad judía. Aún más, si cabe, su importancia crecería, pues como único dato relativo a este final de siglo, conocemos el nombramiento de Maestre Pedro, físico del arzobispo de Toledo, don Pedro Tenorio, como alcalde y juez mayor de todas las aljamas de su arzobispado, en un acto que tuvo lugar en la sinagoga mayor de Alcalá de Henares.

Sin embargo, tanto en 1408 como en 1420, Juan II concedió un privilegio a Gómez Manrique, para que pudiera cambiar $40.000 \mathrm{mrs}$. de juro que tenía situados en las aljamas de judíos y moros de Alcalá, Madrid y Toledo, por otro juro en las alcabalas de Burgos, Santa Gadea, Frómista y otras ciudades, no solamente por la lejanía entre estas dos regiones, sino porque se habia observado un significativo despoblamiento de las aljamas de aquellos lugares ${ }^{22}$. Ahora bien, esta situación, que pudiera ser indicativa de una pérdida de vitalidad de la aljama hebrea de Alcalá a comienzos del siglo $x v$, parece transitoria $y$, además, no se puede extrapolar por entero a la aljama de Alcalá, ya que incluye también a las de Madrid y Toledo, comunidades éstas que sí sufrieron los efectos de las persecuciones de 1391.

La segunda mitad del siglo xv abunda en noticias sobre los judios alcalaínos. Ya en 1440 el concejo obligaba a las aljamas mudéjar y judia a contribuir con la mitad de los gastos que ocasionaba la vela de las puertas de la ciudad.

En el pago del servicio y medio servicio, la aljama de Alcalá, que tributa junto con Loranca y Paracuellos, se consolida como una de las más importantes del Arzobispado de Toledo, llegando a ser la que satisfaga la cantidad más elevada en 1479, con 11.000 mrs. En 1464 y en 1474 pagó $5.000 \mathrm{mrs}$., mientras que en 1472, había alcanzado los $8.000 \mathrm{mrs}$. En 1484 pagó $5.500 \mathrm{mrs}$., en 1485, volvió a abonar 5.500 mrs., la misma cantidad que se contabiliza en 1490, mientras que en 1491, junto con Santorcaz, abonó $6.500 \mathrm{mrs}^{23}$.

21 Ashtor, E: The jews of moslem Spain. II vol. Filadelfia. 1979. pág. 234. El autor no hace ninguna referencia documental que pruebe esta hipótesis.

22 A.H.N. Clero. Perg. Carp. 218. n. 16./A.H.N. Clero. papeles. Leg. 5449.

"Vinuales FerReIRO, Gonzalo: "Los repartimientos del "servicio y medio servicio" de los judíos de Castilla de 1484, 1485, 1490, y 1491", en SEFARAD. 62, (2002), pág. 201. 
También del estudio de la contribución extraordinaria de los castellanos de oro, creada para sufragar los gastos ocasionados por la guerra contra el reino de Granada, se extrae la conclusión de esta favorable coyuntura de la aljama judia complutense. En este caso, tributa también junto a Loranca y Paracuellos, a las que se une Santorcaz. Desde 1486, con 74.956 mrs., hasta 1489, con $78.200 \mathrm{mrs}$., y para todo el territorio castellano, solamente las comunidades hebreas de Zamora, Ávila, Segovia, Soria, Guadalajara, Ocaña, Toledo, Trujillo y Murcia, ingresan en las arcas reales más maravedies que la de Alcalá de Henares. Por el contrario, en 1491, la aljama sólo recaudó 45.000 mrs., síntoma ya de un posible declive final ciertamente acusado.

A lo largo de los últimos cincuenta años del siglo $\mathrm{xv}$, la interrelación entre judios y cristianos fue muy intensa. Son muy numerosos los contratos de censo o de venta de propiedades rústicas o urbanas, así como la activa participación de hebreos en el cobro de diversas rentas que habian arrendado del cabildo catedralicio toledano o del concejo. También durante este período hubo judíos que optaron por bautizarse, ya fuera sinceramente o para mantener su nivel de riqueza, participar de cargos concejiles, etc.

Pero, en 1492 la situación se tornó irremediable. Los judíos debian aceptar la fe católica o abandonar el reino. El decreto de expulsión obligó a muchos judíos alcalainos a malvender sus propiedades y a salir del lugar donde habían morado sus antepasados. Más tarde serán frecuentes los pleitos presentados en el Consejo Real, porque algunos de los judíos que marcharon, aceptaron la conversión en el exilio, y de regreso a Alcalá reclamaron aquello que les había pertenecido legítimamente.

Otros, por su parte, decidieron ya en un primer momento convertirse, y vivir como cristianos; y otros, por último, aunque bautizados no renegaron de su fe. En Alcalá de Henares, la Inquisición procesó entre 1490 y 1535 a diez personas por judaizar, y habilitó a ochenta y cuatro judeoconversos o descendientes de judeoconversos entre 1495 y $1497^{24}$.

\section{LOS JUDIOOS Y EL CONCEJO DE ALCALÁ DE HENARES}

La minoria hebrea no se mantuvo aislada de su entorno. Muy al contrario, procuró integrarse e involucrarse en todas las actividades posibles, sabedora que solamente las buenas relaciones con todos los estamentos de poder, civiles y religiosos, le permitiria subsistir.

El concejo de los hombres buenos de Alcalá de Henares concedió, generalmente, un trato favorable a la población judía. Desde el Fuero Viejo de

24 Cantera Burgos, Francisco, y León Tello, Pilar: Judaizantes del arzobispado de Toledo habilitados por la Inquisición en 1495 y 1497. Madrid. 1969. pp. 110-114. 
1223, al arrendamiento de bienes comunales de fines del siglo xv, pasando por las ordenanzas de 1268, o las disposiciones de 1440, los judios alcalaínos gozaron de una gran igualdad y confianza por parte de las autoridades concejiles.

La primera mención importante de la relación entre el concejo de Alcalá y los judios se encuentra en uno de los enunciados del Fuero Viejo de Alcalá, dado por el arzobispo de Toledo don Rodrigo en 1223, y que no era sino continuación del primero que le diera a la villa el arzobispo don Raimundo en 1135. En esta disposición se regula la caloña que debía pagarse en caso de que un cristiano matara a un judío y viceversa, que son idénticas, como señal más evidente del deseo proteccionista de la población hebrea. Además, se concede la posibilidad de que cualquier judio pueda trasladarse a vivir a la villa complutense ${ }^{25}$.

Pocos años después, el 9 de mayo de 1268, don Sancho, arzobispo de Toledo, promulgaba unas ordenanzas en las que se regulaban diversos aspectos de la vida de Alcalá. De nuevo la alusión a los judíos alcalaínos tiene que ver con aspectos de la justicia; perdura la igualdad en el trato entre cristianos y judios, y sólo se regula la duración temporal de las causas ${ }^{26}$.

Ya en el siglo Xv vuelven a aparecer en la documentación referencias a los judios de Alcalá de Henares, en relación a cuestiones propias del concejo. El 16 de junio de 1421 el arzobispo de Toledo, don Sancho, emitía su sentencia sobre el pleito que había enfrentado a la villa de Alcalá con su tierra acerca de la contribución en los gastos que ocasionaba la reparación de los muros de la villa. Viene hablando en su sentencia de cómo se deben pagar estas reparaciones a partir de los maravedies de las rentas de propios de la villa de Alcalá. Primero, se establece que los bueyes de la ciudad tengan sus pastos acostumbrados; luego, que con el dinero de propios se pague el salario de regidores, procurador, físico, etc. Los demás se deberán emplear en la reparación de la cerca que rodea y protege la villa. $Y$ en este punto, la resolución atañe a la comunidad hebrea pues "[...] si lo que ansi sobrare de los dichos propios non abastare para las dichas reparaciones, o si non sobrare algo, que sea fecho repartimiento por el dicho concejo de la dicha nuestra villa e común della et que los del dicho concejo et aljamas de judios et moros de la dicha nuestra villa paguen de cinco partes la una et los del dicho común paguen las cuatro partes [...]" ${ }^{27}$.

${ }^{25}[$ [..] Todo cristiano vecino que matare o firiere a iudeo a tal caloña: Todo cristiano vecino que matare o firiere a iudeo a tal caloña peche por el iudeo como pechan por vecino cristiano a cristiano. Todo iudeo que matare o firiere a cristiano otra tal caloña peche como cristiano a cristiano. E cristiano que matare a iudeo no es ca enemigo. E iudeo que matare a cristiano non es ca enemigo, e por esto de cristiano e de iudeo con cristiano vecino e con iudeo que more en Alcalá. Firme. E al non vala del cristiano al iudeo o del iudeo al cristiano e de todo iudeo que quisiere morar en Alcalá a en foro more. $E$ al que no semejare vaya en bona ventura o que quisiere. Todo iudez de Alcalá el de los iudeos a derecho e él. e les faga aver derecho e el iudez los juzgue [...] Fuero de Alcalá. Ed. SAEz, C.; CABALLERO, A; ToRRENS, M. Jesús. Alcalá de Henares. 1992. pảg. 107.

${ }^{26}$ Otrossi tenemos por bien e mandamos que quando los cristianos o los judíos ovieren pleito ante los jurados, que judguen hasta medio diá SÁEz, C.: Los pergaminos del archivo municipal de Alcala de Henares. Alcalá. 1990 pág. 48.

27 Ibid. pp. 106-109. 
Poco después, en 1440, con motivo del conflicto que habian sostenido los procuradores del concejo y el procurador de la tierra del común de Alcalá, en relación con la introducción y venta del vino de la tierra en la villa ${ }^{28}$, y sobre las guardas de las puertas y velas de la cerca y palacios de la misma, se redactó una iguala, bajo la presencia y aprobación de don Juan, arzobispo de Toledo, que daba fin a los pleitos abiertos. Los vecinos de la villa de Alcalá y los de la tierra eran equiparados, entre otras cosas en "[...] que en razón de las dichas velas de la dicha cerca e de los dichos palacios de la dicha villa e guardas de las puertas della que de aqui en adelante son o fueren menester en qualquier manera o se ovieren a poner, por mandado del dicho señor arzobispo o por necesidad que recresciere, que el dicho común e adegañas sean tenudos de dar e poner e pagar la meitad de todas ellas; e la otra meitad la ponga e pague la dicha villa, con sus aljamas de judios e moros [... $]^{29}$. En definitiva, las aljamas judia y mudéjar son consideradas, a efectos de la fiscalidad concejil, como partes integrantes de la villa.

Además, las buenas relaciones entre el concejo y la aljama judia se corroboran en el hecho de que, valiéndose de la fecunda formación financiera de los judíos, el concejo confió el cobro de algunas rentas municipales, tales como los arrendamientos de algunas dehesas como las de Alvega, Carramadrid, o la del Sotillo de la Cabeza, así como de los impuestos sobre la leña de las tenerías o el peso y el pesillo, a diecisiete judios de Alcalá, de 1434 a 1466 . Entre ellos, destacaron Abrahem Arévalo, Rabí Hudá, el Dorado, Abraen Gabay, Yuçaf Gabay, Ysaque Xabí. Aunque en los primeros años su participación fue escasa, su intervención fue aumentando progresivamente hasta acaparar en sus manos el cobro del $30 \%$ de los ingresos municipales en 1457 , o del $37 \%$ en $1463^{30}$.

No obstante esta favorable convivencia, en ocasiones existieron también fricciones y disputas. Muy significativo fue el pleito seguido por el concejo, entre otros, contra don Haym Xaví, judio de Alcalá de Henares, pues en 1451 había invadido términos de propios de la villa y había comenzado a labrarlos como si fueran suyos ${ }^{31}$. A este acusado se le menciona en el proceso como «[...] usurpador de tierras que no le pertenecen [... $]^{32}$, pues habia entrado en

28 Acerca de esta cuestión se habia regulado ya en 1419, estableciendo que no se ejecutasen las ordenanzas sobre el vino y el pan, pues los judios pagaban casi todas sus contribuciones respecto al vino. Ahora bien, se mantuvo la prohibición de que ningún judio vendiera vino a cristiano. CASTILLO GOMEZ, A: Alcalá de Henares en la Edad Media. Territorio, sociedad y administración. 1118-1515. Alcalá de Henares. 1989. pp. 259.

29 Ibid. pp. 157-158.

30 Estos datos están tomados de Castillo Gomez, A: Alcalá de Henares en la Edad Media. Territorio, sociedad y administración. 1118-1515. Alcalá de Henares. 1989. pp. 408-411.

31 Parece ser que en la tierra de Alcalá era frecuente el uso de una práctica consuetudinaria, por lo menos hasta 1476, mediante la cual, cualquier vecino de la villa, podía ocupar libremente tierras comunales, y organizarlas según su criterio. Solian ser terrenos sin cultivar o dedicados al cereal, donde los nuevos pobladores plantarian viñas. Vid, SAEZ, C. y CASTILLO, A: "Bienes comunales del concejo de Alcalá de Henares (1476-1481). Explotación y aspectos económicos". Anuario de Estudios Medievales, 19 , (1989). pág. 533

32 Archivo Municipal de Alcalá de Henares (en adelante, A.M.A.H.). Justicia. Leg. 441/1. 
heredades, tierras y ejidos, etc. de Villa Malea, aldea perteneciente a la villa de Alcalá, y se considera este acontecimiento como un agravio para Alcalá, ya que era judio y, como tal, no podia ocupar sin permiso o título de propiedad bienes comunales $^{33}$.

A los testigos se les sometió a un duro interrogatorio de sesenta preguntas, de cuyas repuestas se obtiene una valiosa información de los hechos. En primer lugar, se confirma el uso frecuente de esta práctica, pues Juan Martínez Regañón, contesta diciendo que "[...] puede aver veinte años poco más o menos que era e solia ser e usarse [... $]^{34}$, y se certifica con la declaración de Ferrand Alfonso Señorino quien afirmó "[...] que vido poseer a la dicha Villa Malea, e prados e pastos della, al tesorero Pero Alonso de Vizcaya, e después de él, a Nicolás Diaz, bachiller, y agora, al dicho don Haym, pero que no sabe si tiene títulos algunos [...]" ${ }^{35}$. Respecto a esta última cuestión difieren las declaraciones. Unos testigos consideran que el judío compró la heredad en litigio, ya fuera en almoneda pública o a Juan de Riaño, frente a la opinión de otros que, aunque conocen que don Haym tiene esa tierra, sin embargo, no saben en virtud de qué título, y si lo tuviera dudan de su autenticidad.

En segundo lugar, se pone de manifiesto que aquel que entraba en esos bienes comunales los consideraba como propios. Esteban Ferrández de Ortiz y Garcia Gallego, ambos vecinos de esta villa, coinciden en señalar que don Haym "[...] labra aquella heredad e tiene ende ciertos quinteros [...]", y que saben que "[...] los quinteros del dicho don Haym que defienden que no entren alli ganados algunos desta villa ni de su tierra [... $]{ }^{36}$. Incluso, ha edificado unas casas nuevas, pues, por ejemplo, Juan González de Tapia, se ha extrañado, al pasar junto a Villa Malea, que hubiera edificios recién construídos, para lo cual habia tenido que "romper» algunas tierras.

Y en último lugar, queda patente que no fue el único que actuó de ese modo ${ }^{37}$. Junto con el anterior, se acusa también a don Abrahem Aljabebe, judío, de haber tomado una parcela de tierra de más allá del río, en la que ha plantado árboles y melones, y una parte del camino cercano al río, por donde solía atravesar una carreta cargada (suponemos con mercancias para vender en Alcalá), y que ahora no puede pasar. Este judio tomó también tierras de vecinos de Alcalá, quienes incluso acudieron con oficiales del concejo a comprobar lo que les había sido usurpado.

A.M.A.H. Justicia. Leg. 606/4. Alvar Núnez, notario, vecino de Alcalá de Henares, contesta a la pregunta cuarenta y nueve, que él no ha visto si el dicho don Haym ocupa esas tierras, pero que si lo ocupa, es por mengua del regimiento desta dicha villa, que un judio no podia hacer fuerza a esta villa e su tierra.

34 Ibid.

ibid.

sfi $\mathrm{Ibid}$.

37 En su declaración, Esteban Ferrández de Ortiz acusa a 18 personas de haber cometido los mismos delitos, entre ellos a: don Çuleme Asabad, don Abraen Tarua, don Yuçef Barux y a don Abraen Çalema. No podemos decir si son judios o mudejares, aunque todo parece indicar que se trata de judios. Vid. Archivo Municipal de Alcalá de Henares. Justicia. Leg. 606/4. 
En 1476 don Alfonso Carrillo, arzobispo de Toledo y señor de Alcalá, determinó que esta costumbre atacaba directamente los derechos del concejo, y decidió poner fin a la misma ${ }^{38}$. Confiscó bajo su autoridad cincuenta y cinco parcelas, aunque no expulsó a los usurpadores, sino que a cambio de quedarse les exigió un pago anual de 15 maravedies por aranzada de viña plantada. Aparte de los dos judíos, cuyo caso hemos analizado, en la nómina de aquellos que se convirtieron en censualistas aparecen diez judíos más vecinos de Alcalá de Henares: Menahem Adaroque, Salomón Armero, don Busaf Calax, don Mosé Cohen, Rabi Yuçef, el Dorado, Simuel Leví, Yuçaf Leví, Mira, mujer de Abenosa, Yuçaf Portellano, y don Yova Xaví.

La participación de la minoría hebrea no acaba aquí, pues en la referida nómina encontramos un judío más, vecino de Guadalajara, especiero y proveedor del concejo de Alcalá, llamado Jaco Lerma ${ }^{39}$. Esta notable presencia hebrea en la configuración de estos censos de bienes comunales usurpados, puede obedecer a su directa intervención en los asuntos económicos relativos al concejo, así como a su interés por el trabajo de la tierra, principalmente de estos viñedos, cuyo cultivo redundaría en indudables beneficios. En este sentido, el viñedo se transformó a fires de la Edad Media en un cultivo de calidad, con fácil salida en el mercado, lo que propició su rápida expansión.

\section{LOS JUDIOS DE ALCALÁ Y LA IGLESIA}

La vinculación entre la minoría hebrea alcalaina y la Iglesia fue continua durante los siglos medievales. Como expertos financieros, trabajaron para el arzobispo de Toledo arrendando muchas rentas del cabildo catedralicio. Como meros vecinos de la villa de Alcalá, vivieron en casas que pertenecian a las iglesias de Santiuste (San Justo y San Pastor), o de Santa María, y en otras propiedades que eran de los monasterios de Santa Leocadia y San Francisco, a cambio de un censo anual. No obstante esta colaboración y convivencia, las relaciones no fueron siempre cordiales, pues son numerosas las demandas por falta de pago, llegando incluso a ponerlos en sentencia de excomunión.

\section{Judios de Alcalá arrendadores de las rentas del cabildo catedralicio}

Por lo que se refiere al arrendamiento por parte de los judios de Alcalá de las rentas capitulares, solamente conservamos documentación relativa a la segunda mitad del siglo $\mathrm{xV}$, pero ésta es bastante significativa ${ }^{40}$. A lo largo de estos escasos

\footnotetext{
38 Seguimos para esta cuestión el preciso artículo de Carlos Sáez y Antonio del Castillo, «Bienes comunales del concejo de Alcalá de Henares (1476-1481). Explotación y aspectos socioeconómicos”. Anuario de Estudios Medievales. 19, (1989). pp. 533-558

39 lbid p. 538.

40 Hemos recogido toda la información a partir del libro de la Dra. LEON TELLO, Judíos de Toledo, vol H. Madrid. 1979
} 
cincuenta años, se pueden registrar 48 judíos alcalainos como arrendadores de diversas rentas pertenecientes al cabildo de la catedral de Toledo. Un estudio de los apellidos de estos arrendadores permite comprobar el carácter familiar de esta actividad, que se concentraba en manos de las familias que poseian un mayor nivel socioeconómico dentro de la comunidad judía: Abenarroyo (Çulemán, Mayr, Mosé, Simuel, Todrós, Ysaque y don Yuçaf); Abensabad (Çulemán y don Yuçaf, su hijo); Abenxuxén (Simuel e Ysaque); Alcón (Mosé e Isaac); Arragel (don Mosé, Jaco, su hijo; Simuel, Jaco, su hijo; y Hudá); Çabán (Abraham, Çague, Mosé, su padre; Simuel, Ysaque y Yuçaf); Cohen (Rabi Çag, Mosé, su padre; Simuel y Yuçaf); Francés (Jacob, Mayr, Simuel e Ysaque); Quiñón (Mosé y Yuçaf), y Torica (Abrahem y Haym).

Asimismo aparecen también algunos otros arrendadores judíos, cuyo nombre no coincide con el de ningún otro. Son los siguientes: Hudá Abenosa, Çulemán Abenzara, Ysaque Aladafi, Ysaque Alamán, Abraham de Arévalo, Yuçaf Çahaly, Abrahen Calahorrano, Bueno de Fuentes, Ysaque Gabay, Jaco Harrajal, Samuel Leví, Mosé de Monsoria, y Haym Xabi.

Las rentas que estos judios arrendaron son muy numerosas y variadas a lo largo del período comprendido entre 1445 y 1492. Son, principalmente, las rentas de las ciudades de Alcalá de Henares, Madrid, Guadalajara, Buitrago y Talamanca. También, la renta del pan pontifical, de los excusados de la obra de la iglesia, rentas de los vestuarios y diezmos.

El proceso de arrendamiento consistía en una puja pública entre aquellos que estaban interesados en la percepción de la renta. Si el precio acordado era elevado, se volvía a realizar una nueva compra del derecho de la renta en almoneda pública. Por ejemplo, la renta de Guadalajara de 1465 se remató en 187.976 mrs. en un judio de Guadalajara, Ilamado Simuel Abenarroyo; éste no presentó las fianzas necesarias, por lo que se hubo de volver a subastar, fijándose en $175.000 \mathrm{mrs}$., entre otros, en Ysaque Abenxuxen, judío de Alcalá ${ }^{41}$. Siempre era necesaria la presencia de uno o varios fiadores, distintos de aquel en quien se rematara la renta, que se comprometieran, en caso necesario, a llevar a efecto la tasación aceptada.

Estos grupos de arrendadores, muy bien organizados, no tenian por qué estar integrados exclusivamente por judios de la misma localidad. En el caso alcalaíno, encontramos en estas operaciones a judíos de Alcalá que pujan en subastas de rentas junto a otros de Buitrago, Torrelaguna y Guadalajara. $Y$ no siempre eran hebreos, pues, tanto en Castilla como en Aragón fueron frecuentes las compañías mixtas de arrendadores judios y cristianos.

Ahora bien, los incumplimientos de los contratos fueron muy frecuentes. A partir de la documentación de la catedral de Toledo, dada a conocer por la Dra.

41 Op. cit., vol. II. pág. 326. 
León Tello, se observa que el cabildo mantuvo constantes pleitos con arrendadores judíos, por no terminar de pagar las cantidades acordadas, y ordenó medidas de enorme severidad contra ellos. Por ejemplo, en 1469 se procedía contra Ferránd López Huerta e Ysaque Gabay, quienes tenian una deuda superior a los 25.000 mrs., y se les apremia a que la salden en el plazo de seis dias. Como éstos no la abonaran, el vicario general en el arzobispado de Toledo les excomulga y ordena "[...] que nadie tenga trato con ellos, en comer ni beber, ni conversar ni departir y no les vendan pan, agua, sal, vino ni otra clase de mantenimiento [...]" ${ }^{42}$; y en 1483 y 1484 el procedimiento contra Samuel Leví, quien debía 200.000 mrs. de la recaudación de la hermandad de Alcalá. Los procedimientos contra arrendadores judíos alcalaínos fueron numerosos, pudiendo ser citados, entre otros, los casos de Mosé Alfón, Ysaque de Arévalo y Paloma, su mujer, Çulemán Abensabad, Jaco Francés, y Mosé de Monsoria.

\section{Judios de Alcalá censatarios de la colegial de Santiuste}

Otra de las principales conexiones de los judíos con la iglesia colegial de la villa complutense se encuentra en el hecho de que fueron muchos los que habitaron en casas cuya propiedad pertenecía al cabildo, a cambio del pago de un censo anual. Estos censos son, además, unas de las fuentes principales para delimitar el espacio físico ocupado por pate de la comunidad judia de Alcalá de Henares.

La mención más antigua a los judíos alcalaínos en una carta de censo data de 1401. Aunque no participan judíos directamente en el contrato, se mencionan unas casas que había comprado la colegial a don Çag, el Conqui, en la cal pública de la judería ${ }^{43}$. Sin embargo, la gran mayoría de los contratos de censo corresponden a la segunda mitad del siglo XV, pincipalmente a la década de los años ochenta, y muchos se han conservado gracias a un documento posterior que recoge un inventario de censos de esta iglesia ${ }^{44}$. Se pueden contabilizar veintisiete judíos que durante la segunda mitad del siglo $x v$ recibieron en censo diversos bienes inmuebles urbanos pertenecientes a la Iglesia de san Justo y san Pastor. Los censos se realizaban a perpetuidad, y en todas las ocasiones los judios cumplieron con sus obligaciones contractuales, que solían consistir en pagos en dinero (maravedies) y en especie (gallinas).

También hay algunas cartas de censo referidas a propiedades rústicas del cabildo de la colegial en la tierra de Alcalá. Así, en 1469 el cabildo de san Justo y san Pastor daba en censo a Mosé Bitón, judio de Alcalá, un "[...] pedazo de tierra con fasta cuarenta cepas que hay en el pago de Valdemeco [...]. " ${ }^{45}$; y en

42 LEON TELLO, P: Judios de Toledo vol. Il. Madrid. 1979. p. 391.

43 A.H.N. Clero. Carp. 1341. N. 7.

44 Vazouez Madruga. M. Jesús: Archivo y patrimonio de la lglesia colegial de san Justo y san Pastor de Alcalá de Henares en 1493. Alcalá de Henares. 1993.

45 A.H.N. Clero. Leg. 3563. 
1478, Yuça Leví, especiero, vecino de Alcalá, permutaba con la iglesia colegial una carta de censo que había tenido sobre "[...] dos pedazos de viña en el pago de la Rinconada [...]" ${ }^{46}$, por otra carta de censo sobre una casa.

\section{Judios y cristianos en Alcalá de Henares}

Como hemos tenido ocasión de comprobar, las relaciones entre la población hebrea de Alcalá y la cristiana fueron a lo largo de la Edad Media cercanas y fluidas. Los judios vivian entremezclados con los cristianos, compartiendo patios y calles; poseian tierras de labor en medio de las propiedades de cristianos, y arrendaron rentas del rey o del arzobispo formando, con frecuencia, compañias mixtas con cristianos. Incluso, las disposiciones de los fueros y ordenanzas igualaron en casos concretos la condición jurídica entre ambos grupos.

Los judíos alcalaínos no padecieron las violencias callejeras del pogrom de 1391. Tampoco se aplicó en esta villa el ordenamiento de las Cortes de Toledo de 1480 relativo al apartamiento de los judíos en barrios aislados, ya que, según ponen de manifiesto las cartas de censo mencionadas, los judíos continuaron habitando las casas en donde habían vivido hasta esa fecha, rodeados de vecinos tanto cristianos como moros.

Sin embargo, se observa un aumento de las tensiones cristiano-judias, en las fechas inmediatas a la promulgación del decreto de expulsión. En marzo de 1492, los Reyes Católicos ordenaban al concejo de Alcalá que devolviera a los judios de Trujillo Yuçé el moço y Salomón Mayr la mitad de los bienes que le habian sido confiscados en la villa a su madre, doña Vellida, quien había acudido a cobrar una deuda en Alcalá, siendo alli apresada y ajusticiada por el corregidor ${ }^{47}$. Y en mayo del mismo año, era asesinado en Alcalá un converso, hijo de un judio llamado Yuçaf Triguero ${ }^{48}$; no es posible determinar, sin embargo, si el asesinato está relacionado con su condición de judeoconverso, o si obedece a otras diversas motivaciones.

\section{Judeoconversos y judaizantes alcalainos}

Las aparentemente buenas relaciones entre cristianos y judios contribuyeron a que el problema converso no alcanzara una elevada magnitud en la villa de Alcalá de Henares antes de 1492. Las menciones más antiguas referidas a conversos alcalaínos datan de los últimos lustros del siglo xv; aparecen entonces desempeñando diversos oficios o acensando propiedades comunales. Gozaban, por tanto, de una saneada posición socio-económica.

A.H.N. Clero. Leg. 3553.

77 Archivo General de Simancas. (en adelante, A.G.S.). Registro General del Sello. (en adelante, R.G.S.). fol. 441

48 lbid. fol. 186 
El número de conversos en los reinos hispánicos creció considerablemente tras la expulsión. De acuerdo a una pragmática de los Reyes Católicos del 10 de noviembre de 1492, se permitió regresar a aquellos judíos expulsos que hubieran optado por bautizarse ${ }^{49}$. A éstos se les tenía que devolver sus bienes, a cambio del pago de las cantidades que habían obtenido por su venta al salir del reino, así como las mejoras que los compradores hubieran podido hacer en ellos, pues la premura de la marcha les habia llevado a vender sus posesiones por cantidades muy inferiores al valor que se creía justo («justo precio») ${ }^{50}$.

Las quejas de los conversos se elevaron hasta los monarcas. Se reclaman heredades, casas, tiendas, viñas y rentas, que eran de su propiedad o que habian heredado, y se iniciaron procedimientos para estimar el valor de la venta, probar su legalidad, y si debía restituirse el bien al demandante o no. Esta actitud facilitó el aumento de la hostilidad para con los judeoconversos. Así se observa en Alcalá, pues en 1495, solicitaban a los Reyes Católicos que controlaran ciertas actitudes promovidas por «[...] algunas personas de esta villa que a fin de poner escándalo en el pueblo para que los roben y maten, dice que han hecho e inducido a un fraile que predica en esta villa que diga en los sermones que hacen muchas cosas feas y enormes contra ellos y que ha puesto muchos alborotos, de manera que dice que los llaman judíos o tornadizos y los marginan, siendo ellos buenos cristianos $[\ldots], 51$.

Ahora bien, no todos los judeoconversos renegaron de su fe pasada. Ya hemos mencionado como en Alcalá de Henares la Inquisición procesó entre 1490 y 1535 a diez personas por judaizar, y habilitó a otras ochenta y cuatro personas entre 1495 y 1497 . Esta lista se ampliaría hasta ciento seis si añadimos a las personas «abonadas» que acompañan a los habilitados. Aparte de la cuantiosa nómina de cristianos nuevos, destaca el elevado nivel socioeconómico de éstos.

El Tribunal del Santo Oficio recaudó por habilitaciones en la villa complutense $178.000 \mathrm{mrs}$., con una media de $2.119 \mathrm{mrs}$. por persona. Teniendo en cuenta que solía establecerse como pena por la habilitación un $5 \%$ de la fortuna del condenado, es posible suponer que casi el $50 \%$ de los judeoconversos habilitados gozaba de rentas superiores a los $50.000 \mathrm{mrs}$., y un $27 \%$ de rentas ingresaba entre 10.000 y 50.000 mrs. ${ }^{52}$.

49 A partir de la lectura de los procesos de la Inquisición observamos que muchos de estos judios habian abandonado Castilla por Portugal, y que después de permanecer alli por un breve periodo de tiempo, y ante la inminencia de una nueva migración, una vez trascurridos los ocho meses para los que habian sido autorizados a instalarse en Portugal, se convirtieron, y decidieron regresar a Alcalá con sus familias.

So VIÑUAles FerReiro. Gonzalo: "El regreso de judeoconversos tras la expulsión de 1492: Ios "retornados" a la diócesis de Toledo" en El Olivo, XXVIII, 60, (2004), pp. 93-114.

51 A.G.S. R.G.S. fol. 173

52 CARFASCO, R: “Solidaridades judeoconversas y sociedad local» en Inquisición y conversos, III Curso de cultura hispano-judia y sefardi. Toledo. 1993. p. 77. También ofrece un cuadro de porcentajes de rentas de judeoconversos habilitados, CAstillo, A: Alcalá de Henares en la Edad Media. Territorio, sociedad y administración. 1118-1515. Alcalá de Henares. 1989. p. 412. 
Las actividades profesionales que desempeñaban se enmarcan, preferentemente, dentro del sector artesanal (tejedores, colcheros, zapateros, y pellejeros), y del sector terciario (doctores, escribanos, mercaderes, y alcaides), en una proporción equilibrada. Entre éstos, y de acuerdo a la cantidad de pago, podemos afirmar, junto con Antonio Castillo ${ }^{53}$, que gozaron de un nivel mayor de ingresos aquellos que centraron su ejercicio profesional en el sector servicios. Por otro lado, los judeoconversos desempeñaron un importante papel en el gobierno municipal de la villa, pues algunos de los procesados y habilitados de Alcalá de Henares ocuparon cargos como los de procurador, regidor, alcalde o escribano, lo que confirma su alto nivel socio-cultural y su deseo de integrarse en la vida concejii ${ }^{54}$.

\section{Los judios de Alcalá de Henares: sociedad y economia}

Diversos factores pudieron incidir en el temprano asentamiento de la población hebrea de Alcalá de Henares: su posición geográfica, a caballo de Toledo y Guadalajara, ciudades que conocieron la presencia de importantes comunidades judias; la privilegiada posición ocupada por la villa alcalaína desde el punto de vista de las rentas mercantiles; las favorables condiciones jurídicas otorgadas a los hebreos en los fueros y primitivas ordenanzas municipales; o su carácter de villa dependiente de la jurisdicción de los arzobispos de Toledo, quienes a lo largo de toda la Baja Edad Media favorecieron la presencia hebrea en las ciudades y villas sujetas a su autoridad. Sin embargo, resulta harto complejo el estimar, siquiera de forma aproximada, la población global de judios en Alcalá durante la Edad Media; y para ello nos valemos de las cantidades que pagaron en concepto de "servicio y medio servicio" y "servicio de los castellanos de oro", asi como de cálculos proporcionales en virtud de los padrones de judios que se han conservado (Cáceres y Talavera). También, los datos que nos suministran los procesos de la Inquisición, o las listas de habilitación, nos ofrecen una valiosa información indirecta.

Utilizando el padrón de judíos de Talavera de la Reina, Fernando Suárez cifra la población judia de Alcalá de Henares en 1477-1478 en 336 vecinos pecheros, lo que daría lugar, empleando un coeficiente de 5 miembros por familia, a una población total de unos 1.680 judios. En 1495 el Santo Oficio habilitó a 84 vecinos de la villa por judaizantes; si tenemos en cuenta que muchos judios se habian marchado ya, es muy posible que para 1492 la cifra de hebreos que habitaban en Alcalá alcanzara las setecientas personas. Además, la amplia extensión de la judería, que ocupa el centro vital y mercantil de la villa, corrobora esta significativa presencia semita en Alcalá de Henares.

53 Ibid. pp. 229-230.

54 Por ejemplo, Gonzalo de Torres habia sido regidor en 1476, y Juan López Huerta (=Ysaque Gabay), lo fue en 1492 y 1498 . 
Las actividades profesionales desempeñadas por los judios alcalainos fueron muy amplias y diversas. Compraron, recibieron en censo, e incluso usurparon tierras y majuelos para plantar principalmente viñas, o para llevar a pastar allí a sus ganados. Ya hemos visto como en el pleito por usurpación de tierras en Villa Malea, Haym Xabí se hizo con propiedades del concejo y no permitió pasar alli a otros ganados que los suyos; o como en una carta de censo de 1473 sobre unas tierras del cabildo de Santiuste, se mencionan las viñas de los hermanos Simón y Hudá Alpullate. Este documento nos dice que Simón era carnicero, por lo que es posible que fueran propietarios de tierras pero que no las trabajaran directamente.

Asimismo los judios destacaron en la actividad mercantil. Llegaron a Alcalá como comerciantes, y así se mantuvieron durante más de quinientos años. En casi todas las cartas de censo que contratan los judios se alude a casas o casas-tienda, ubicadas muchas en la calle Mayor. Es muy posible que el taller artesanal se situara en el interior de la vivienda, en su planta baja, y que ésta tuviera un escaparate al exterior donde dar salida a los más diversos productos, como especias, telas, muebles, objetos de plata, zapatos, etc. ${ }^{55}$

También ejercieron como físicos y cirujanos, demostrando su sabiduría en el arte de la medicina. Otros fueron maestros de la Ley, que enseñaban en sus sinagogas. Pero la dedicación más caracteristica de un sector de los judíos de Alcalá de Henares fue el arrendamiento de rentas reales, catedralicias y municipales; esta actividad era desarrollada por unas cuantas familias de elevada posición económica, a las que les reportaba importantes beneficios. Otro importante sector profesional era el artesanal, de menor capacidad económica, pero de una extremada comunión y solidaridad entre si. Anecdótico, pero muy clarificador de este aspecto, es el hecho de que en 1485 Abrehem Arroques diera la posesión de un censo que él tenía dado en Alcalá a Vellida, su sobrina, "[...] para ayuda a su casamiento [... $]^{56}$. 